\title{
Manual bamboo cutting tool
}

\author{
Mariana Pereira Bezerra ${ }^{\mathrm{a}}$ Walter Franklin Marques Correia ${ }^{\mathrm{b}}$ and Fabio Ferreira da Costa Campos ${ }^{\mathrm{c}}$ \\ ${ }^{a}$ Undergraduate student, Federal University of Pernambuco; mariana.pbezerra@gmail.com \\ ${ }^{\mathrm{b}}$ D. Sc; Federal University of Pernambuco; design10@terra.com.br \\ ${ }^{\mathrm{c}}$ Federal University of Pernambuco; ffcc@ieee.org
}

\begin{abstract}
The paper presents the development of a cutting tool guide, specifically for the harvest of bamboo. The development was made based on precepts of eco-design and ergonomics, for prioritizing the physical health of the operator and the maintenance of the environment, as well as meet specific requirements of bamboo. The main goal is to spread the use of bamboo as construction material, handicrafts, among others, from a handy, easy assembly and material available tool.
\end{abstract}

Keywords: Bamboo, ecodesign, ergonomics, cutter tool.

\section{Introduction}

The ABERGO classifies ergonomics as "the study of the adaptation of work to physiological and psychological characteristics of human beings." This work takes place in various environments and conditions. In these environments, the greater the diversity of tasks to be performed, the greater the diversity of the rich that the operator will be submitted.

These data can be applied to agricultural work, including the planting of bamboo, which is the plant with fastest growing on earth and belongs to the group of renewable materials. Its characteristics as plant and its remarkable properties as material indicate a range of potential use to meet a development which would lower production costs, improving the environment, among others.

Following the ecological appeal for which the consumer today, products that use structural and aesthetic characteristics of bamboo are released frequently. Most of the basics of using eco-design throughout the project.

The proposed work is at the junction of these three areas, aiming at the development of a manual cutting tool, specific to the bamboo, which meets the needs of farm worker.

\section{Bamboo}

Bamboo is a plant of the grass family, which protects the soil, sequesters carbon quickly and can be used along with other woods in reforestation. It is also able to provide food and raw materials of good quality and can contribute to avoid cutting more pronounced tree and tropical forests.
According to Choy et al (2005), the high speed of growth is what sets it apart from almost all plants of its kind, reaching in some types, a growth rate of more than one meter in height in less than 24 hours. In Brazil, one sees a growth of certain species, about $37 \mathrm{~cm}$ in less than 24 hours.

As raw material, bamboo has been used for centuries in the production of a plethora of artifacts, whether utilitarian or decorative. By having a tubular feature, it adds functions and adjustments inherent in its own way. Having its composition basically made of long fibers can be molded or shredded for new applications.

Asia is the continent which has a longer tradition in the work and handling of bamboo, especially Japan and China. In some this plant is included in various government programs for research and development related to their cultivation and industrial use.

According to Jahn (2001) Brazil is today the largest number of types of bamboo found and cataloged in Latin America. However, despite this variety, the potential of this plant in Brazil is still little explored and exploited, compared with the uses that are made in other countries, such as East Asia.

In Brazil, the exploitation of bamboo practically limited to traditional uses such as crafts, tutors in agriculture and temporary constructions. The most significant exception is the production of paper duplex board of Bambusa vulgaris by a northeastern company with an installed capacity of 72 thousand tons annually.

Contrary to this situation, architects, engineers, and some researchers have been studying and confirming the great economic and social potential 
of this raw material. However, many of the products created, although disclose the qualities of bamboo as a renewable raw material, do not appreciate the non-aggression to the environment, championed by ecodesign.

\section{Ecodesign}

Ecodesign is the method of designing, which aims to prevent or reduce the environmental impacts. It is not just to "clean" but mostly "not dirty", taking this into account at all stages of design by.

White suggests a number of criteria by which it is possible to assess whether a product has the characteristics that make it sustainable.

Are considered sustainable products in the logic of ecodesign, and according to the understanding of ecodesign team-net, those who have, where applicable, among others, the following characteristics:

1. Eliminates or reduces the formation along the product life cycle (from production of raw materials to post-use), the formation of waste, in particular non-recyclable;

2. Use raw materials and inputs ecologically sustainable (eg, certified wood);

3. Minimizes the solutions adopted, the possibility of misuse, accidents and excessive physical expenditures to the user and the worker;

4. Provides solutions that rationalize the use of natural raw materials;

5. Allows the replacement of parts reducing the formation of waste. Facilitates maintenance and reuse / recycling;

6. Offers quality, objectivity, creativity and innovative solutions to externalize (by formal aspects, functional and communication), the concepts of eco-design;

7. Meets specific ecodesign or with respect to sustainable production;

8. Facilitates dismantling;

9. Prioritize the use of accessible technologies and materials (cost-benefit and culture of the users and producers).

\section{Ergonomics}

Ergonomics is consolidated as a scientific discipline that is involved with all human activities, at work, at home, in sports and leisure. Born during World War 2, due to the need to better match / interaction between man and machine, but widespread among civil society, has come to include capital goods industries and consumer goods.

Today, with ever more mechanized processes, ergonomics is essential in any job. Among these posts, is agricultural work, in which, the greater the diversity of tasks to be performed, the greater the diversity of risks to which the operator will be submitted. This work tasks are loosely structured, in most cases require considerable physical effort, awkward posture, repetitive operations with active instruments in a short time, among others.

Some ergonomic risk factors in this environment are: shareholder, displacement, environmental, labor accident. Harvesting bamboo has most of these risks, and risks associated exclusively with this plant. For example, the difficulty of achieving the culms (stems) in the right age for harvest, which are concentrated in the center of the bush.

\section{Proposal for cutting tool}

According to Pereira \& Garbino (2002), cut the stalks of bamboo can be done with a chainsaw, ax, saw or with a machete. However, these tools appreciate the quality of the material collected, without worrying about the health of the operator.

Furthermore, production, storage and disposal of the tool are not intended to maintain or protect the environment.

Thus, the proposal seeks to develop a tool that reduces the requirement biomechanics operator, meeting the basic requirements of bamboo, easy to assemble and whose disposal does not harm the environment.

Aiming to assist the development of friendly tools, anthropometry said some basic rules, including:

- Motion control is generally performed by the hands and feet, thus, should be natural.

- Controls for more forces are triggered activation with muscles of the arms or legs, levers or pedals.

According to Lia Buarque M. Guimaraes, the handle must have the form and location that will allow a good posture for the hands and arms. If the handle is the palms strength exercise, the diameter should be $3 \mathrm{~cm}$ and length $10 \mathrm{~cm}$. One should not use tools with straight grip, which requires twisting the handle. It indicated the use of tools with curved handle so that the wrist is straight.

The tool, designed, is made of bamboo in its natural state, due to easy access of the material for the producers and the possibility of discharge directly into the environment without harming it. See pictures 1 and 2 in the Annex.

The operator will handle the tool holding the rod vertically, and cut the bamboo with the help of a blade, located in cross section, and fixed with two bolts. This extended horizontal rod base will support the forearm of the operator, so there is no twist of the tool while cutting. Thus, the effort will be applied along the forearm of the operator, and not on your wrist. The tool has also an upper horizontal rod, keeping the operator's hand slipping during handling.

Following the precepts of ecological design, materials and structure of the tool allow the exchange of worn parts separately as the cutting 
blade, for example, making it unnecessary to dispose of the entire artifact. Its storage is also facilitated by this modular structure.

\section{Conclusion}

The main goal of this work is to spread the use of bamboo as a building material, crafts, among others, from a handy tool, easy to assemble and available material. The health of rural workers can not be forgotten, as well as the maintenance of the environment. It is hoped, also, a greater acceptance of bamboo, not just the poor, but in all spheres of society, demystifying the material image of its poor quality.

\section{Acknowledgements}

We thank the National Council for Scientific and Technological Development (CNPq) for their financial support, enabling the realization of this and other research in the area.

\section{References}

[1] PEREIRA, Marco A. R. Bamboo Body and Soul. Bauru, 2008.

[2] Salles, Douglas. Ergonomics applied to cut sugar cane. Paranaense XXII Day of Occupational Health.

[3] REGIS, Frederick Menezes. Ecodesign: The potential of bamboo. Salvador, 2004.

[4] WHITE, Alcaeus. Evaluation criteria for sustainable products - ecodesign

[5] http://www.cgecon.mre.gov.br/pvt/home. File captured on November 18, 2003

[6] Guimarães, Lia Buarque de Macedo. Product Ergonomics. PPGEP

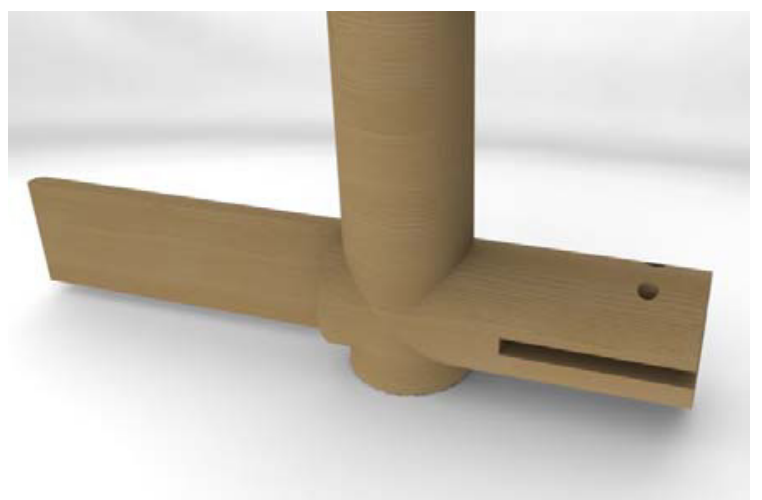

Figure 2: Detail of cross section, located on the stem base, and perpendicular to the vertical shaft.

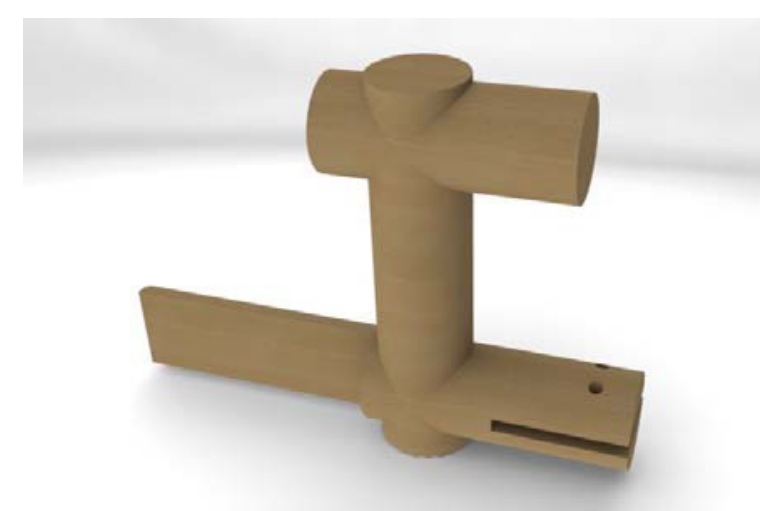

Figure 1: Cutting Tool Manual 